\title{
Optimization and Interpretation of Fenton and UV/Fenton Processes for Degradation of Syringyl Lignin
}

\author{
Wang $C^{1^{*}}$, Zhang $S^{1}$, Zhang $Z^{1}$, Zeng $M^{1}$ and Yuji $S^{2}$ \\ ${ }^{1}$ College of Marine Science and Engineering, Tianjin University of Science and Technology, Tianjin 300457, China \\ ${ }^{2}$ Department of Environmental and Energy Chemistry, Kogakuin University, Tokyo 192-0015, Japan
}

*Corresponding author: Chang Wang, College of Marine Science and Engineering, Tianjin University of Science and Technology, Tianjin, China, Tel: +862260273320; E-mail: wangc88@163.com

Rec date: 21 July, 2014, Acc date: 15 August, 2014, Pub date: 17 August, 2014

Copyright: @ 2014 Wang C et al. This is an open-access article distributed under the terms of the Creative Commons Attribution License, which permits unrestricted use, distribution, and reproduction in any medium, provided the original author and source are credited.

\begin{abstract}
The performances of syringyl lignin degradation by using Fenton and UV/Fenton processes were investigated in a self-designed cylindrical reactor. Many factors including $\mathrm{pH}$, dosage of $\mathrm{H}_{2} \mathrm{O}_{2}$, concentration of $\mathrm{Fe}^{2+}$ initial concentration of syringyl lignin, reaction time and UV irradiation were optimized to reach the removal efficiency of syringyl lignin up to $87.5 \%$. Specifically the optimum reactor time was $60 \mathrm{~min}$, dosage of $\mathrm{H}_{2} \mathrm{O}_{2}$ was two times of its theoretical quantity and molar ratio of $\left[\mathrm{Fe}^{2+}\right] /\left[\mathrm{H}_{2} \mathrm{O}_{2}\right]$ was $1: 50$ at $\mathrm{pH} 3$. Furthermore, introducing UV-light into the Fenton system significantly improved the decomposition of syringyl lignin with the removal efficiency of $100 \%$ in first $30 \mathrm{~min}$. In addition, the degradation mechanism of syringyl lignin by Fenton process was discussed in detail by using UV-visible spectroscopy and TOC analysis. It was found that syringyl lignin was oxidized by electron transfer of complex intermediates which contained high valence iron in homogeneous Fenton system.
\end{abstract}

Keywords: Fenton process; Homogeneous system; Syringyl lignin mechanism; Paper making wastewater

\section{Introduction}

In China, paper industry is not only one of the most important industries for national economy increasing, but also a major consumer of water resource, which produces environmental pollutants with various organic pollutants discharged in wastewater. The Chemical Oxygen Demand (COD) emission in China is reported to arrive at 719 thousand tons in 2010 which accounts for $20.3 \%$ of the national industrial emissions. The pollutant of paper-mill wastewater accounts for $90 \%$ of the total pollutants, causing a serious threat to people's health and ecological security [1].

Among the complex compositions of discharged wastewater from papermaking industries, lignin is the most difficult compound to be biodegraded due to its structure with phenyl propane [2,3]. The present treatment technique for papermaking wastewater is still limited owing to complex production processes, high operation cost, and high concentration of toxic substances. Nowadays, physicochemical methods are widely used for the treatment of papermaking wastewater. For example, Fenton oxidation process as an advanced oxidation technology has its superiorities in dealing with non-biodegradable organic matters, due to advantages of simple operation, accessible reagents, low treating cost, free of complicated equipment and low toxicity to the subsequent biochemical treatment. Fenton reaction mechanism and reaction rates were well concluded by Sychev et al. [4]. As a result, Fenton oxidation has been successfully used in a variety of industrial wastewater treatments [5-7]. Meanwhile, $\mathrm{UV}$ is introduced into Fenton system to improve performance of advanced oxidation process, since $\mathrm{H}_{2} \mathrm{O}_{2}$ can be efficiently decomposed into -OH under the irradiation of UV to enhance oxidation of Fenton reagent. The UV/Fenton process was reported to be more efficient than Fenton process but caused a comparatively high cost [8].
Additionally, $\mathrm{Fe}^{3+}$ generated from the reaction can form complex ion $\mathrm{Fe}(\mathrm{OH})^{2+}$ with $\mathrm{OH}$ at low $\mathrm{pH}$. These complex ions are transformed into $\mathrm{Fe}^{2+}$ producing $-\mathrm{OH}$ under $\mathrm{UV}$, which not only improves $\mathrm{Fe}^{2+}$ concentration to enhance the catalytic performance of Fenton system, but also increases the amount of $-\mathrm{OH}$.

Based on preliminary experimental study for the degradation of guaiacol [9], syringyl lignin from paper making wastewater was selected as a target compound in this study, which is a significant generated substance in the papermaking process. So far, study on degradation of syringyl lignin by Fenton process is still quite limit with few results and discussion. The homogeneous Fenton oxidation process was innovatively carried out in a self-designed cylindrical reactor, by using UV-Vis spectrophotometer to quantify syringyl lignin and discover potential complex intermediates. A number of potential factors that may impact the removal efficiency of syringyl lignin were investigated and optimized, including initial $\mathrm{pH}$ value, dosage of $\mathrm{H}_{2} \mathrm{O}_{2}$, concentration of $\mathrm{Fe}^{2+}$, initial concentration of syringyl lignin, reaction time and UV irradiation. Furthermore, the mechanism of syringyl lignin degradation by Fenton and UV/Fenton reaction has been initially explored by analyzing the change of UV-visible spectral of syringyl lignin during the degradation and comparing removal efficiency and mineralization efficiency of syringyl lignin.

\section{Methods and Materials}

\section{Reactor set-up}

The degradation of syringyl lignin by Fenton and UV/Fenton processes was carried out in a double glass heat-resistant reactor (Figure 1).

The outer layer was the circulated cooling water (diameter $10 \mathrm{~cm}$, temperature $20^{\circ} \mathrm{C}$ ), and the inner was the reaction zone (height $15 \mathrm{~cm}$, inner diameter $8 \mathrm{~cm}$ and total volume $750 \mathrm{~cm}^{3}$ ). A high pressure 
mercury lamp (TianJing ZiJing Special Light Source ZSZ, China) was introduced into UV/Fenton system to provide UV light. The nominal power of ultraviolet lamp was $11 \mathrm{w}$. Solution was mixed by a thermostatic magnetic mixer (Shanghai Sile Instrument 85-2, China).

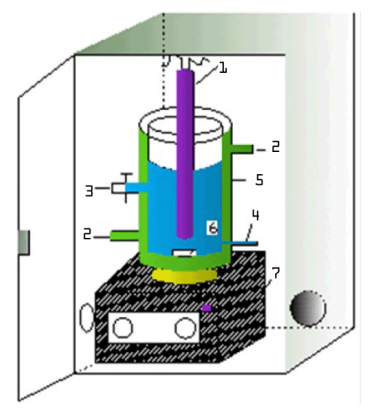

Figure 1: Diagram of Photocatalytic reactor 1. Ultraviolet lamp; 2. Circulating cooling water; 3. Sampling place; 4 . Aeration place; 5. Reactor zone; 6. Magnetic stirrer; 7. Magnetic mixer.

The formula of syringyl lignin (SL) is $\mathrm{OHC}_{6} \mathrm{H}_{3}\left(\mathrm{OCH}_{3}\right)_{2}$ and its main structure contains a phenyl alkoxy, a phenolic hydroxyl group and a methoxy group with the maximum absorption wavelength $\lambda_{\max }=267 \mathrm{~nm}$, whose molecular structure is shown in Figure 2.<smiles>COc1cccc(OC)c1O</smiles>

Figure 2: Molecular formula of syringyl lignin

\section{Treatment design}

Syringyl lignin (analytical purity, Nanjing Odyssey Chemical Industry Co., Ltd) was dissolved in $500 \mathrm{~mL}$ deionized water in the photocatalytic reactor that was place on the thermostatic magnetic mixer. Sulfuric acid (analytical purity, Tianjin Yingdaxigui Chemical Reagent) or $\mathrm{NaOH}$ (analytical purity, Tianjin Kaitong Chemical Reagent Co., Ltd.) was used to adjust $\mathrm{pH}$ to be 2.0, 3.0, 4.0, 5.0, 6.0, 9.0 and 10.0, respectively. In this test, other factors were controlled to be $[\mathrm{SL}]=50 \mathrm{mg} / \mathrm{L},\left[\mathrm{H}_{2} \mathrm{O}_{2}\right]=2.0 \mathrm{Q}_{\text {th }}$ and $\left[\mathrm{Fe}^{2+}\right] /\left[\mathrm{H}_{2} \mathrm{O}_{2}\right]=1: 50$.

Then $10 \mathrm{mg} / \mathrm{L} \mathrm{FeSO}_{4}$ (analytical purity, Tianjin Beifang Chemical Reagent) was added and stirred uniformly in solution. The molar ratio of $\left[\mathrm{Fe}^{2+}\right] /\left[\mathrm{H}_{2} \mathrm{O}_{2}\right]$ was changed to $1: 100,1: 80,1: 50,1: 25$ and $1: 20$, respectively in conditions of $[\mathrm{SL}]=50 \mathrm{mg} / \mathrm{L},\left[\mathrm{H}_{2} \mathrm{O}_{2}\right]=2.0 \mathrm{Q}_{\mathrm{th}}, \mathrm{pH}=3$ and reaction time for Fenton and $\mathrm{UV} /$ Fenton $=60 \mathrm{~min}$ and $30 \mathrm{~min}$, respectively.

Theoretical $\mathrm{H}_{2} \mathrm{O}_{2}$ amount $\left(\mathrm{Q}_{\mathrm{th}}\right)$ is the required amount of $\mathrm{H}_{2} \mathrm{O}_{2}$ to completely oxidize the organic pollutant into $\mathrm{CO}_{2}$ and $\mathrm{H}_{2} \mathrm{O}$. Taking syringyl lignin solution as an example, according to Eq. (1), 198.7 $\mathrm{mg} / \mathrm{L} \mathrm{H}_{2} \mathrm{O}_{2}$ was needed to completely mineralize syringyl lignin to $\mathrm{CO}_{2}$ and $\mathrm{H}_{2} \mathrm{O}$. Considering the density of $\mathrm{H}_{2} \mathrm{O}_{2}(30 \% \mathrm{w} / \mathrm{w})$ of 1.110 $\mathrm{g} / \mathrm{mL}$, theoretical $\mathrm{H}_{2} \mathrm{O}_{2}$ amount was $0.6 \mathrm{~mL} / \mathrm{L}$.

$\mathrm{C} 8 \mathrm{H} 10 \mathrm{O} 3+18 \mathrm{H} 2 \mathrm{O} 2 \rightarrow 8 \mathrm{CO}_{2}+23 \mathrm{H}_{2} \mathrm{O}(1)$
Dosage of $\mathrm{H}_{2} \mathrm{O}_{2}$ in the study was based on this theoretical amount and different amounts of $\mathrm{H}_{2} \mathrm{O}_{2}(30 \% \mathrm{w} / \mathrm{w})$ (analytical purity, Tianjin Beifang Chemical Reagent) were added into Fenton and UV/Fenton systems: $0.25 \mathrm{Q}_{\text {th }}, 0.5 \mathrm{Q}_{\text {th }}, 1.0 \mathrm{Q}$ th, $2.0 \mathrm{Q}_{\text {th }}$ and $3.0 \mathrm{Q}_{\text {th }}$ in conditions of $[\mathrm{SL}]=50 \mathrm{mg} / \mathrm{L},[\mathrm{Fe} 2+] /[\mathrm{H} 2 \mathrm{O} 2]=1: 50, \mathrm{pH}=3$ and reaction time for Fenton and UV/Fenton $=60 \mathrm{~min}$ and $30 \mathrm{~min}$, respectively.

For sample analysis, $5 \mathrm{~mL}$ solution was taken separately at reaction time of $5,10,20,30,60$ and $90 \mathrm{~min}$ in conditions of $[\mathrm{SL}]=50 \mathrm{mg} / \mathrm{L}$, $\left[\mathrm{H}_{2} \mathrm{O}_{2}\right]=2.0 \mathrm{Q}_{\text {th }}$, $\left[\mathrm{Fe}^{2+}\right] /\left[\mathrm{H}_{2} \mathrm{O}_{2}\right]=1: 50$ and $\mathrm{pH}=3$, and then mixed with $\mathrm{Na}_{2} \mathrm{SO}_{3}$ to terminate the reaction.

\section{Physicochemical analysis}

UV/Vis spectra were recorded by using an UV-Vis spectrophotometer (LabTech UV-1000, USA) pH was measured by an acidimeter (Tianjin Shengbang Technology pHS-3C, China). Total organic carbon (TOC) was measured by a TOC analyzer (OI Analytical 1010, USA). TOC values were mainly represented by nonpurgeable organic carbon (NPOC).

Absorbance value of solution was measured at a wavelength of 267 $\mathrm{nm}$. The removal efficiency of syringyl lignin could be calculated according to Eq. (2)

\section{Removal efficiency $=(\mathrm{C} 0-\mathrm{C}) / \mathrm{C} 0 \times 100 \%$ (2)}

Where $\mathrm{C} 0$ was the mass concentration of syringyl lignin solution before the reaction, $\mathrm{mg} / \mathrm{L}$; $\mathrm{C}$ was the mass concentration of syringyl lignin solution after the reaction, $\mathrm{mg} / \mathrm{L}$.

The intermediates during degradation process were difficult to be monitored by gas chromatography or liquid chromatography, because they may instantly disappear or their concentrations are too low to be detected in the organic phase after the samples were extracted with organic solvent. So, UV-visible spectrophotometer and TOC analyzer were used to investigate the degradation process in this study. The samples were scanned by UV-visible spectrophotometer at the wavelength ranging from 200 to $600 \mathrm{~nm}$.

\section{Results and Discussion}

\section{Initial pH}

The effect of different initial $\mathrm{pH}$ on removal efficiency of syringyl lignin is shown in Figure 3, Which indicates that the removal efficiency of syringyl lignin was significantly high at $\mathrm{pH}$ 3.0-4.0 with the maximum value of $87.5 \%$ at $\mathrm{pH}=3.0$. However, the removal efficiency of syringyl lignin was $43.2 \%$ and almost zeros at pH 6.0 and 2.0 , respectively. This phenomenon could be explained by two reasons, $\mathrm{Fe}^{2+}$ starts to precipitate under alkaline condition with the increase of $\mathrm{pH}$, and thus it can significantly reduce catalytic decomposition of $\mathrm{H}_{2} \mathrm{O}_{2}$. Besides, $\mathrm{H}_{2} \mathrm{O}_{2}$ is not stable in alkaline solution and is decomposed into $\mathrm{O}_{2}$ and $\mathrm{H}_{2} \mathrm{O}$ and thus lose oxidative capacity [10]. Regarding with extreme low $\mathrm{pH}$, it enhances the stability of $\mathrm{H}_{2} \mathrm{O}_{2}$ and slows decomposition of $\mathrm{H}_{2} \mathrm{O}_{2}$ to produce $-\mathrm{OH}$, resulting in the decrease of removal efficiency of syringyl lignin. In addition, the high concentration of $\mathrm{H}^{+}$inhibits the reduction of $\mathrm{Fe}^{3+}$ to $\mathrm{Fe}^{2}$. Therefore, $\mathrm{H}_{2} \mathrm{O}_{2}$ and $\mathrm{Fe}^{2+}$ are difficult to form an effective redox system under a high or extreme low $\mathrm{pH}$ condition. In this study, optimized $\mathrm{pH}$ value for Fenton process was assumed to be 3.0. Similarly, Jung et al. [11] found that $\mathrm{pH}$ buffered to acidic condition maintained relatively high levels of dissolved iron in the aqueous solution, contributing to 
effective production of hydroxyl radical and degradation of organic contaminants.

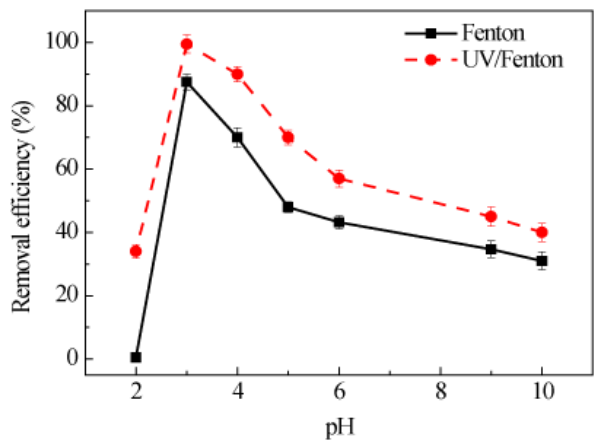

Figure 3: Effect of different initial $\mathrm{pH}$ value on the removal efficiency of syringyl lignin in conditions of $[\mathrm{SL}]=50 \mathrm{mg} / \mathrm{L}$, $\left[\mathrm{H}_{2} \mathrm{O}_{2}\right]=2.0 \mathrm{Q}$ th and $[\mathrm{Fe} 2+] /\left[\mathrm{H}_{2} \mathrm{O}_{2}\right]=1: 50$.

Figure 3 also shows that the syringyl lignin degradation in UV/ Fenton system was very efficient with removal efficiency up to $100 \%$ at the same $\mathrm{pH}$ of 3.0 in Fenton system. Introducing ultraviolet light in Fenton system contributed to comparative high removal efficiency at extreme high and low $\mathrm{pH}$.

\section{$\mathrm{H}_{2} \mathrm{O}_{2}$ dosage}

As shown in Figure 4, the removal efficiencies of syringyl lignin increased at first and then decreased along with the increase of $\mathrm{H}_{2} \mathrm{O}_{2}$ dosage in both systems, and finally reached a maximum value at the $\mathrm{H}_{2} \mathrm{O}_{2}$ amount of $2.0 \mathrm{Q}_{\text {th }}$. Although the high $\mathrm{H}_{2} \mathrm{O}_{2}$ concentration was reported to be a dominating parameter for the high removal efficiency of phenol by Fenton's reagent [12], its adding concentration should be estimated. Because $\mathrm{H}_{2} \mathrm{O}_{2}$ can both generate and eliminate $-\mathrm{OH}$, optimum $\mathrm{H}_{2} \mathrm{O}_{2}$ amount to yield high concentration of -OH stayed in a certain range. When the dosage of $\mathrm{H}_{2} \mathrm{O}_{2}$ exceeds this range, further $\mathrm{H}_{2} \mathrm{O}_{2}$ addition leads to scavenging effect on -OH, resulting in decrease of $-\mathrm{OH}$ utilization. Therefore it is extremely important to select an appropriate concentration of $\mathrm{H}_{2} \mathrm{O}_{2}$. According to the result of experiment, good treatment effect efficiency can be achieved when the dosage of $\mathrm{H}_{2} \mathrm{O}_{2}$ is $2.0 \mathrm{Q}_{\text {th }}$

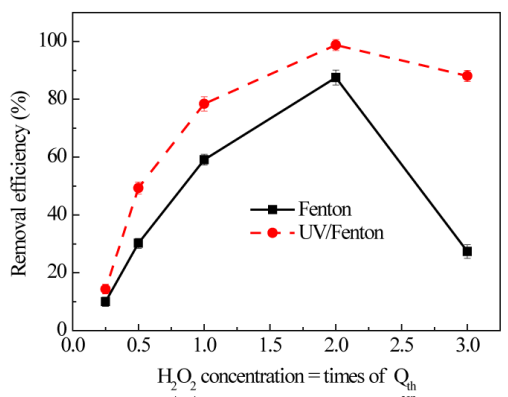

Figure 4: Effects of different hydrogen peroxide concentration on the removal efficiency of syringyl lignin in conditions of $[\mathrm{SL}]=50$ $\mathrm{mg} / \mathrm{L},\left[\mathrm{Fe}^{2+}\right] /\left[\mathrm{H}_{2} \mathrm{O}_{2}\right]=1: 50, \mathrm{pH}=3$ and reaction time for Fenton and $\mathrm{UV} /$ Fenton $=60 \mathrm{~min}$ and $30 \mathrm{~min}$, respectively

\section{$\left[\mathrm{Fe}^{2+}\right] /\left[\mathrm{H}_{2} \mathrm{O}_{2}\right]$ ratio}

The effect of different concentrations of $\mathrm{Fe}^{2+}$ on removal efficiency of syringyl lignin is shown in Figure 5, which indicates that the removal efficiency of syringyl lignin increased at first and then decreased as the concentration of $\mathrm{Fe}^{2+}$ increases, and finally reached a maximum value at $\left[\mathrm{Fe}^{2+}\right] /\left[\mathrm{H}_{2} \mathrm{O}_{2}\right]=1: 50$. Consequently, $\mathrm{Fe}^{2+}$ was a necessary element to catalyze the generation of radical. Otherwise, $\mathrm{H}_{2} \mathrm{O}_{2}$ was hard to decompose to generate radical without $\mathrm{Fe}^{2+}$. Additionally, the changing trend of curves was similar to the curve in Figure 4. When the dosage of $\mathrm{Fe}^{2+}$ was low, the removal efficiency of syringyl lignin continuously increased due to the accumulation of generated $-\mathrm{OH}$, whereas excessive $\mathrm{Fe}^{2+}$ was detrimental to the removal efficiency because the oversupplied $\mathrm{Fe}^{3+}$ yields $\mathrm{Fe}^{2+}$ that may act as a significant scavenger by quenching the $-\mathrm{OH}$. Another reason is that excessive concentration of $\mathrm{Fe}^{2+}$ promotes $\mathrm{H}_{2} \mathrm{O}_{2}$ decomposing into large amount of $-\mathrm{OH}$. Thus a high concentration of $-\mathrm{OH}$ leads to scavenging effect by itself. Both reasons lead to a decline in utilization efficiency of $-\mathrm{OH}$. Chan et al. [13] suggested that the oxidation capacity of Fenton process had a nonlinear correlation to the doses of $\left[\mathrm{Fe}^{2+}\right] /\left[\mathrm{H}_{2} \mathrm{O}_{2}\right]$ due to the involvement of some unwanted side reactions at both high and low $\left[\mathrm{Fe}^{2+}\right] /\left[\mathrm{H}_{2} \mathrm{O}_{2}\right]$ ratios. So appropriate dosage of $\mathrm{Fe}^{2+}$ is necessary to increase the reaction efficiency and reduce the cost of wastewater treatment at the same time.

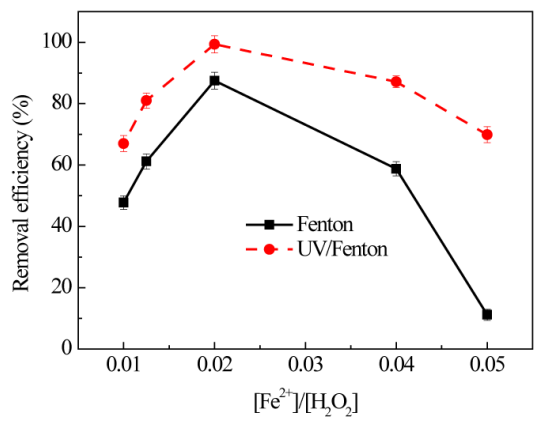

Figure 5: Effects of different concentration of $\mathrm{Fe}^{2+}$ on the removal efficiency of syringyl lignin in conditions of $[\mathrm{SL}]=50 \mathrm{mg} / \mathrm{L}$, $\left[\mathrm{H}_{2} \mathrm{O}_{2}\right]=2.0 \mathrm{Q}_{\mathrm{th}}, \mathrm{pH}=3$ and reaction time for Fenton and UV/ Fenton $=60 \mathrm{~min}$ and $30 \mathrm{~min}$, respectively.

\section{Reaction time}

The effect of reaction time on removal efficiency of syringyl lignin is shown in Figure 6 which demonstrates that the removal efficiency of syringyl lignin was more than $70 \%$ and about $54 \%$ in UV/Fenton and Fenton system, respectively after $30 \mathrm{~min}$, indicating the high rate of reaction at the beginning of Fenton reagent. After 30 min, syringyl lignin was totally removed in UV/Fenton system, while the removal efficiency of syringyl lignin in Fenton reaction increased to the maximum value about $87 \%$ at $60 \mathrm{~min}$. This phenomenon suggests that Fenton reaction was very quick, and $-\mathrm{OH}$ produced during the reaction could basically oxidize syringyl lignin in the first $60 \mathrm{~min}$ of the reaction, after that the concentration of $-\mathrm{OH}$ decreased and it slowed down the reaction rate. 


\section{Comparison in different systems}

In order to understand the role of $\mathrm{Fe}^{2+}$ and UV in Fenton system, the removal efficiency of syringyl lignin was separately investigated in $\mathrm{H}_{2} \mathrm{O}_{2}$, homogeneous Fenton and homogeneous UV/Fenton system. The comparison of removal efficiency of syringyl lignin in different systems is also shown in Figure 6.

$\mathrm{H}_{2} \mathrm{O}_{2}$ system only contributed to the removal efficiency being about $21.7 \%$. But the removal efficiency was significantly improved after addition of $\mathrm{Fe}^{2+}$ with removal efficiency up to $87.5 \%$ at 60 min, which was 4 times higher than that in $\mathrm{H}_{2} \mathrm{O}_{2}$ system. Moreover, the removal efficiency of syringyl lignin was even higher when UV irradiation was introduced into the Fenton system, where syringyl lignin was completely removed in first $30 \mathrm{~min}$. Similarly, Hu et al. [14] compared $\mathrm{UV} /$ Fenton, $\mathrm{UV} / \mathrm{H}_{2} \mathrm{O}_{2}$ and Fenton reagent to treat landfill leachate, who suggested that the UV/Fenton process was the most effective approach oxidation process to enhance the biodegradability and eliminate the color of the leachate. This is in accordance to the theory that UV irradiation can efficiently enhance the decomposition of $\mathrm{H}_{2} \mathrm{O}_{2}$ to produce $-\mathrm{OH}$, which consequently increases the oxidation of syringyl lignin. Meanwhile, complex ion $\mathrm{Fe}(\mathrm{OH})_{2}$ formed by $\mathrm{Fe}^{3+}$ and $\mathrm{OH}$ at $\mathrm{pH} 3$ also produces $-\mathrm{OH}$ and $\mathrm{Fe}^{2+}$ under $\mathrm{UV}$ irradiation. Thus the catalytic capacity of Fenton was enhanced to improve the removal efficiency of syringyl lignin.

\section{Interpreting degradation of syringyl lignin}

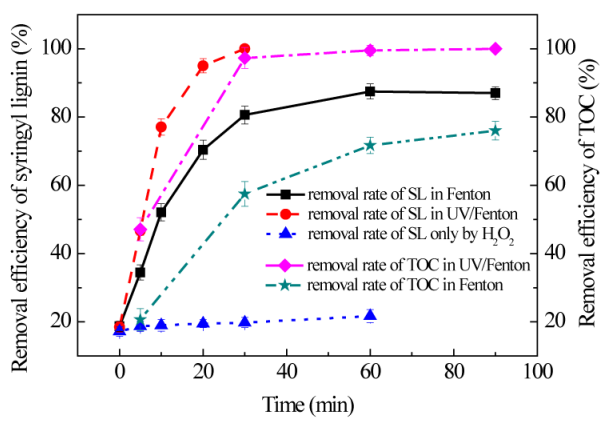

Figure 6: Removal efficiencies of syringyl lignin and TOC in different oxidation processes along reaction time in conditions of $[\mathrm{SL}]=50 \mathrm{mg} / \mathrm{L},\left[\mathrm{H}_{2} \mathrm{O}_{2}\right]=2.0 \mathrm{Q}_{\mathrm{th}},\left[\mathrm{Fe}^{2+}\right] /\left[\mathrm{H}_{2} \mathrm{O}_{2}\right]=1: 50$ and $\mathrm{pH}=3$

By comparing removal efficiencies of syringyl lignin and TOC in Fenton and UV/Fenton system in Figure 6,

It can be found that the removal efficiency of TOC was lower than that of syringyl lignin in Fenton and UV/Fenton systems. This phenomenon proposes a hypothesis that syringyl lignin was degraded into some other organic intermediates first and then completely mineralized slowly instead of one-step oxidizing syringyl lignin into $\mathrm{CO}_{2}$ and $\mathrm{H}_{2} \mathrm{O}$. Therefore, further analysis was done to reveal the mechanism by analyzing UV-Vis spectra.

The UV-Vis spectra of UV/Fenton system are shown in Figure 7a, which demonstrates the absorption peak of syringyl lignin at around $267 \mathrm{~nm}$ immediately disappeared once $\mathrm{H}_{2} \mathrm{O}_{2}$ was added into the system and a strongly absorbed spectral band was detected in the range of 200-400 nm simultaneously. It can be inferred that a large amount of complex intermediates was generated with a strong absorption in UV-Vis range. The absorbance decreased rapidly in the first $30 \mathrm{~min}$ of reaction and then kept stable, which implies that conjugate structure of phencyclidine is destroyed by oxidation of UV and Fenton reagent. According to Figure 6, the mineralization efficiency reached $100 \%$ after $30 \mathrm{~min}$, indicating that syringyl lignin was completely mineralized; however the absorption spectrum bands in ultraviolet regions still existed and the colorless solution immediately turned to brown as $\mathrm{H}_{2} \mathrm{O}_{2}$ was added. So it can be concluded that the Fenton reaction is not a simple radical reaction. Combining with the theory of other researchers [15-17], an assumption was proposed that a complex $(\mathrm{Fe}$ is $+\mathrm{IV}$ or $+\mathrm{V})$ with a large absorption spectra band was generated by the reaction of $\mathrm{Fe}$ (II) and syringyl lignin. The pollutant was oxidized by electron transfer of complex compound, which is another important pathway of Fenton reaction.

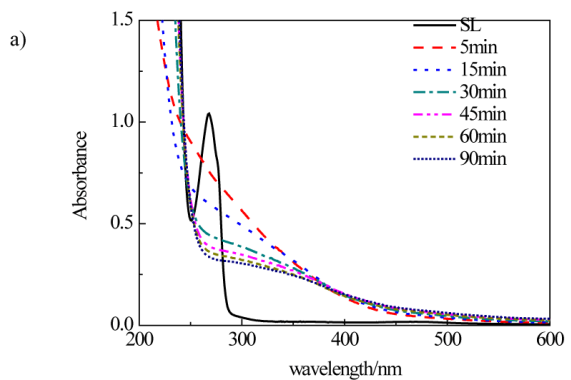

Figure 7(a): UV-Vis spectra in homogeneous UV/Fenton reaction in conditions of $[\mathrm{SL}]=50 \mathrm{mg} / \mathrm{L},\left[\mathrm{H}_{2} \mathrm{O}_{2}\right]=2.0 \mathrm{Q}_{\mathrm{th}},\left[\mathrm{Fe}^{2+}\right] /\left[\mathrm{H}_{2} \mathrm{O}_{2}\right]=1: 50$ and $\mathrm{pH}=3$

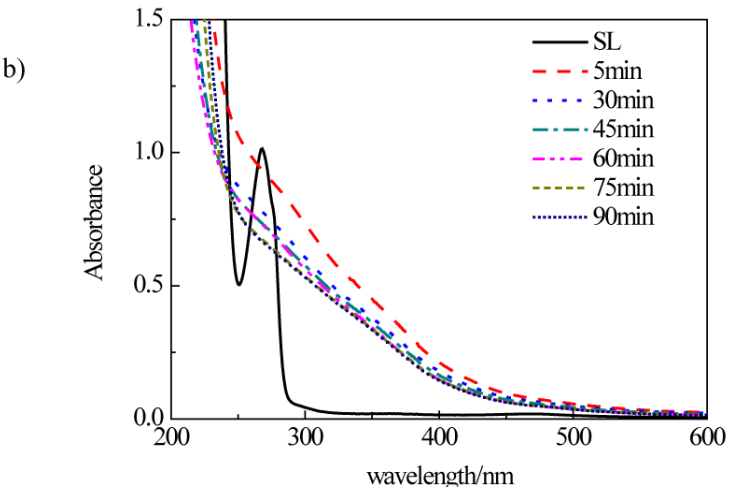

Figure 7(b): Homogeneous Fenton reaction in conditions of $[\mathrm{SL}]=50 \mathrm{mg} / \mathrm{L},\left[\mathrm{H}_{2} \mathrm{O}_{2}\right]=2.0 \mathrm{Q}_{\text {th }},\left[\mathrm{Fe}^{2+}\right] /\left[\mathrm{H}_{2} \mathrm{O}_{2}\right]=1: 50$ and $\mathrm{pH}=3$

The UV-Vis spectra of syringyl lignin changing with the time of Fenton reaction are shown in Figure 7b, Which shows that the UV-Vis spectral change of syringyl lignin in homogeneous Fenton system was very similar to UV/Fenton system? The absorption peak at $267 \mathrm{~nm}$ disappeared when $\mathrm{H}_{2} \mathrm{O}_{2}$ was added into the system, suggesting that the reaction mechanisms of both systems are similar. However, a larger absorbed spectral band was detected in the range of $250-600 \mathrm{~nm}$ in Fenton system than that in UV/Fenton system in the range of 250-400 $\mathrm{nm}$, suggesting that the oxidation of UV/Fenton was stronger than 
Citation: Wang C, Zhang S, Zhang Z, Zeng M, Yuji S (2014) Optimization and Interpretation of Fenton and UV/Fenton Processes for Degradation of Syringyl Lignin. J Environ Anal Chem 1: 115. doi:10.4172/2380-2391.1000115

Page 5 of 5

Fenton reaction, and the synergistic effect between UV and Fenton reagent improved the removal efficiency of organic compounds.

\section{Conclusion}

The factors in Fenton and UV/Fenton processes such as initial $\mathrm{pH}$ value, dosage of $\mathrm{H}_{2} \mathrm{O}_{2}$ and $\mathrm{Fe}^{2+}$, reaction time and $\mathrm{UV}$ irradiation were optimized in a self-designed cylindrical reactor. The optimum factors including dosage of $\mathrm{H}_{2} \mathrm{O}_{2}$ of $2.0 \mathrm{Q}_{\text {th }}(0.6 \mathrm{~mL}),\left[\mathrm{Fe}^{2+}\right] /\left[\mathrm{H}_{2} \mathrm{O}_{2}\right]$ ratio of 1:50, initial $\mathrm{pH}$ of 3.0, and reaction time of $90 \mathrm{~min}$ gave rise to removal efficiency of syringyl lignin being $87.5 \%$. UV irradiation increase the removal efficiency of syringyl lignin that was completely removed in first $30 \mathrm{~min}$. Reaction mechanisms of both Fenton system and UV/ Fenton system were similar, that complex intermediates ( $\mathrm{Fe}$ is $+\mathrm{IV}$ or $+\mathrm{V}$ ) were generated with a large absorption spectra band when $\mathrm{H}_{2} \mathrm{O}_{2}$ was added. Thus syringyl lignin was degraded into organic intermediates firstly and then completely mineralized slowly instead of one-step oxidized into $\mathrm{CO}_{2}$ and $\mathrm{H}_{2} \mathrm{O}$. The present study is believed to provide a valuable foundation for the treatment of papermaking wastewater by Fenton reagent.

\section{References}

1. Hou Y, Zhao H, Bai H, Zhang L, Tang H (2012) Papermaking Effluent Treatment: A New Cellulose Nanocrystalline/Polysulfone Composite Membrane. Procedia Environmental Sciences 16: 145-151.

2. Eskelinen K, Särkkä H, Kurniawan T, Sillanpää M (2010) Removal of recalcitrant contaminants from bleaching effluents in pulp and paper mills using ultrasonic irradiation and Fenton-like oxidation, electrochemical treatment, and/or chemical precipitation: A comparative study, Desalination 255: 179-187.

3. Ninomiya K, Takamatsu H, Onishi A, Takahashi K, Shimizu N (2013) Sonocatalytic-Fenton reaction for enhanced $\mathrm{OH}$ radical generation and its application to lignin degradation, Ultrasonics Sonochemistry 20: 1092-1097.

4. Sychev AY, Isak VG (1995) Iron compounds and the mechanism of the homogeneous catalysis of the activation of $\mathrm{O} 2$ and $\mathrm{H} 2 \mathrm{O} 2$ and of the oxidation of organic substrates, Russ. Chem. Rev 64: 1105

5. Maezono T, Tokumura M, Sekine M, Kawase Y (2011) Hydroxyl radical concentration profile in photo-Fenton oxidation process: Generation and consumption of hydroxyl radicals during the discoloration of azo-dye Orange II, Chemosphere 82: 1422-1430.

6. Masomboon N, Ratanatamskul C, Lu MC (2010) Chemical oxidation of 2,6-dimethylaniline by electrochemically generated Fenton's reagent, Journal of Hazardous Materials 176: 92-98.

7. Shih Y, Ho C, Huang Y (2013) Photo-Fenton oxidation of azo dye reactive black $\mathrm{B}$ using an immobilized iron oxide as heterogeneous catalyst, Water Environment Research 85: 340-345.

8. Gogate PR, Pandit AB (2004) A review of imperative technologies for wastewater treatment II: hybrid methods, Advances in Environmental Research 8: 553-597.

9. Wang C, Liu F (2009) Oxidative degradation of guaiacol with Fenton process, Transactions of China Pulp and Paper 24: 72-76.

10. Sanja P, Dinko V, Natalija K, Danijel S (2009) Decolourization and mineralization of commercial reactive dyes by using homogeneous and heterogeneous Fenton and UV/Fenton processes, Journal of Hazardous Materials 164: 1137-1145.

11. Jung YS, Lim WT, Park JY, Kim YH (2009) Effect of pH on Fenton and Fenton-like oxidation, Environmental Technology 30: 183-190.

12. Kumar P, Nikakhtari H, Nemati M, Hill GA (2010) Oxidation of phenol in a bioremediation medium using Fenton's reagent, Environmental Technology 31: 47-52.

13. Chan $\mathrm{KH}, \mathrm{Chu} \mathrm{W}$ (2003) The dose and ratio effects of $\mathrm{Fe}(\mathrm{II})$ and $\mathrm{H} 2 \mathrm{O} 2$ in Fenton's process on the removal of atrazine, Environmental Technology 24: 703-710.

14. Hu XL, Wang XF, Ban YX, Ren BZ (2011) A comparative study of UVFenton, UV-H2O2 and Fenton reaction treatment of landfill leachate, Environmental Technology 32: 945-951.

15. Bossmann SH, Oliveros E, Sabine G, Siegwart S, Dahlen EP, et al. (1998) New evidence against hydroxyl radicals as reactive intermediates in the thermal and photochemically enhanced Fenton reactions, The Journal of Physical Chemistry A 102: 5542-5550.

16. Chen L, Zhou MH, Lei LC (2006) Evidence against hydroxyl radical mechanism in photo-Fenton degradation of p-chlorophenol, Journal of Environmental Sciences 18: 388-391.

17. Wang C, Zhang S, Sakai Y, Zhang Z (2014) Analysis of a complex produced in the Fenton oxidation process, Water Science \& Technology doi:10.2166/wst.2014.019. 